\title{
EVALUATION OF BEHAVIOR AND WELFARE IN BROILERS REARED IN TWO DIFFERENT HOUSING SYSTEMS
}

\author{
SARA E. EL-KAZAZ \\ Animal and Poultry Behaviour and Management, Department of Animal Husbandry and Animal Wealth \\ Development, Faculty of Veterinary Medicine, Alexandria University, Alexandria, Egypt.
}

Received: 31 March 2018; Accepted: 30 April 2018

\begin{abstract}
ABSTARCT
An experiment was conducted to evaluate the effect of different housing system (cages vs. floor system) on behavioral patterns and welfare of broiler chicks. One hundred and twenty broiler were allocated in to two housing system (cages and floor pen) in full environmental controlled pens for four weeks. Assessment of welfare was through measuring general behavioral, tonic immobility test and heterophil: lymphocyte ratio (HLR). Compared to cage reared birds, floor reared broilers exhibit higher level of feeding, drinking, crouching, walking behavior while caged birds were more often standing and also showed either more wing stretch, leg stretch or both wing\& leg stretch than floor reared group. Moreover, shortest duration of tonic immobility test was observed in floor reared birds than those housed in cages. HLR were significantly higher in cages than floor group. At the end of this experiment our obtained data suggested that housing in cages has adverse effect on welfare as it impair general behavioral patterns, birds showed more fearfulness also higher HLR which over all indicated stressful conditions for birds. In conclusion, cages should not be recommended for broiler rearing from welfare point of view.
\end{abstract}

Key words: Behavior, tonic immobility, broiler housing system, welfare, H/ L ratio.

\section{INTRODUCTION}

Current intensive poultry production systems that aim to maximize profit offer new solutions which increase productivity. Demands for meat quality and standard welfare level have increased in whole world. Production systems have to meet minimum husbandry standard such as low stocking rate, slowgrowing bids, food stuff low in fat high in cereals, minimum slaughter age 81 days (Fanatico et al., 2007). However, these systems do not meet the natural needs of birds. Ignoring welfare of birds not only an ethical issue but it also affects directly on weight gain, health and behavior of birds. Broilers chicken are reared in many systems according to factors, there are two basic systems of rearing broilers, floor litter system and cages. Generally, floor system requires more floor space, but it is very satisfactory for bird's welfare and motivation for exhibit important behavioral activities. On other hand, large-scale commercial poultry farm whose aim to intensify production are characterized by increase stocking density, cage housing, lack of outdoor areas,

Corresponding author: Dr. SARA E. EL-KAZAZ

E-mail address: saraelkazaz2@gmail.com

Present address: Animal and Poultry Behaviour and Management, Department of Animal Husbandry and Animal Wealth Development, Faculty of Veterinary Medicine, Alexandria University, Alexandria, Egypt. restricted movement, mechanization of handling are some disadvantage of housing which act as stress factor in cages (Swain et al., 2002).

Behavioral data is a good index for bird welfare evaluation and contribute to explain data of production and economy (Wegner, 1992). Moreover, freedom from fear has been identified by animal welfare council as one of five freedoms important for animal welfare (Webster and Nicol, 1988). Also welfare can be monitored in different housing system by measuring some physiological parameters that used for estimating stress such as Heterophil and lymphocyte ratio (HLR) which are both indicators for stress used for assessment of animal comfort and welfare (Hester et al., 1996; Al-Murain et al., 1997 and Campo et al., 2007).

Also evaluation of rearing environment from the welfare viewpoint may be based on the fear level in birds. For evaluating fear a tonic immobility test has become widely used (Jones and Mills 1983 and Mills and Faure 1986). Tonic immobility (TI) is a fearpotentiated response induced by physical restraint (Jones and Faure 1981). The TI test is based on a natural defensive reaction used by birds living in the wild when remain completely motionless to dissuade the predator (anti-predator behavior) to protect themselves from attacking. Its duration is considered to be positively related to the fear state, the more 
frightened the bird the longer it will remain freeze (Gallup and Maser 1979, Jones 1986, Jones 1992). Therefore, this study aim to assess broiler behavior and welfare under two different housing system (floor and cage) by measuring behavioral patterns, fearfullness by tonic immobility test and one of physiological stressors indicators such as heterophil / lymphocyte ratio.

\section{MATERIALS AND METHODS}

\section{Birds and hosing:}

A total number of 120 chicks of commercial flocks divided in to two groups each of about 60 mixed sex chicks at 2 week of age were used in this experiment. Chicks were supplied to the farm by commercial hatchery. On arrival, broiler chicks were raised up to two weeks in fully controlled housing system. Then they were transferred to two housing system cage and floor litter pen. Duration of experiment was from 2 week till six week of age.

\subsection{Cage housing system:}

Broiler cage house consists of 3 vertical tires with six birds per cage. In each cage fitted with a front feeding trough with two drinking nipples and with movable belt underneath each tire for manure collection with total number of 60 birds.

\subsection{Floor pen housing system:}

A litter of straw with $10 \mathrm{~cm}$ depth was used. Flock was housed at a stocking density 16 birds $/ \mathrm{m} 2$. Feeder and waterer were allocated; feed and fresh water were free access to birds. Birds received starter, grower and finisher rations which formulated to meet their requirements stated in broiler management guide. The 2 flocks were received 12 hours natural light and dark respectively.

\section{Measured parameters:}

\subsection{Behavioral measurement:}

Behavioral patterns were recorded using scan sampling, behavioral observation start at 9 am scanned for 1 min with 10 min interval with total of $120 \mathrm{~min} /$ pen/day twice a week for 4 weeks. Behaviors observed are feeding, drinking, crouching, standing idle, walking, and comfort behavior such as leg stretch, wing stretch and both wing and leg stretch.

\subsection{Tonic immobility test (TI):}

Ten birds from each housing system randomly collected at 6 week of age (end of experiment). They were brought to separate room and the procedure of this test was conducted as described by Jones and Faure (1981). Birds were placed on a table on their back and gently restraining it by hand for 15 second, raising their necks by a towel warped underneath; their head was dropped down from the edge of the table. The hand was then removed and the observer remain silent and fix his eye on the bird in order to fear-inducing properties of the eye contact could achieve. In this test the time elapsed till the bird raised up again after removal of the hand until the bird straightened up and number of trails did by the bird for rising was recorded using stop watch to record latencies until the bird up righted itself.

\subsection{Physiological parameters:}

At the end of experiment, 10 birds from each treatment were randomly selected and blood sample were collected via wing vien in tubes containing EDTA as anticoagulant prepared for using maygrunwand Giemsa stain. One hundred leukocytes including granular (heterophil, oesinophils and basophils) and non-granular (lymphocytes and monocytes) were counted on one slide for each bird and the heterophil / lymphocyte ratio (HLR) was calculated.

\section{Statistical analysis:}

T-test independent used to analyze the effect of floor and cage system on behavioral patterns, tonic immobility test and HLR using SAS, software 1996 (SAS Institute Inc., Cary, NC, USA). Values were presented as mean $\pm \mathrm{SD}$. A level of significant as minimal acceptable level was assessed at $(p<0.05)$.

\section{RESULTS}

Table 1: Proportions (\%) of birds performing different behavioral activities (Mean \pm SD) of broilers reared on floor and cage housing systems.

\begin{tabular}{ccc}
\hline Behavioral activities & Cage & Floor \\
\hline Feeding & $10.67 \pm 3.22^{\mathrm{b}}$ & $13.82 \pm 3.21^{\mathrm{a}}$ \\
\hline Drinking & $4.11 \pm 1.33^{\mathrm{b}}$ & $7.32 \pm 1.33^{\mathrm{a}}$ \\
\hline Standing & $17.06 \pm 4.07^{\mathrm{a}}$ & $4.56 \pm 1.05^{\mathrm{b}}$ \\
\hline crouching & $51.36 \pm 10.65^{\mathrm{b}}$ & $69.32 \pm 17.12^{\mathrm{a}}$ \\
\hline Walking & $2.36 \pm 0.96^{\mathrm{b}}$ & $8.89 \pm 1.99^{\mathrm{a}}$ \\
\hline Wing stretch & $7.23 \pm 0.53^{\mathrm{a}}$ & $3.49 \pm 0.24^{\mathrm{b}}$ \\
\hline Leg stretch & $5.36 \pm 0.84^{\mathrm{a}}$ & $4.59 \pm 0.57^{\mathrm{b}}$ \\
\hline Wing \& Leg stretch & $8.23 \pm 1.35^{\mathrm{a}}$ &
\end{tabular}

Means bearing different litters within the same raw are significantly different $(\mathrm{P}<0.05)$ 
Table 2: Physiological indices of broilers reared on floor and cage housing systems (Mean \pm SD).

\begin{tabular}{ccccc}
\hline Housing system & Heterophil & Lymphocyte & Heterophil: lymphocyte & Basophil \\
\hline Cage & $38.29 \pm 3.36^{\mathrm{a}}$ & $52.60 \pm 4.21^{\mathrm{b}}$ & $0.69 \pm 0.04^{\mathrm{b}}$ & $6.32 \pm 1.01^{\mathrm{a}}$ \\
\hline Floor & $29.21 \pm 3098^{\mathrm{b}}$ & $72.13 \pm 5.74^{\mathrm{a}}$ & $0.39 \pm 0.02^{\mathrm{a}}$ & $3.21 \pm 0.94^{\mathrm{b}}$ \\
\hline
\end{tabular}

Means bearing different litters within the same raw are significantly different $(\mathrm{P}<0.05)$

Table 3: Means $( \pm$ SD) of tonic immobility test $(\mathrm{TI})$ in broilers reared in floor and cage housing system.

\begin{tabular}{ccc}
\hline Housing system & Duration of TI & Attempts of induction \\
\hline Cage & $168.75 \pm 38.83^{\mathrm{b}}$ & $1.00 \pm 0.01^{\mathrm{ab}}$ \\
\hline Floor & $141.32 \pm 32.16^{\mathrm{a}}$ & $2.1 \pm 0.11^{\mathrm{a}}$ \\
\hline
\end{tabular}

Means bearing different litters within the same raw are significantly different $(\mathrm{P}<0.05)$

\section{DISCUSSION}

1. Behavioral patterns: Behavior describing data is important for analysis of bird welfare. Behavioral measurement of broilers under two housing system are shown in Table (1). Compared to caged broilers, floor reared bird's exhibited more feeding, drinking, crouching, and walking. As birds housed in cages exhibited poorer behavioural patterns because they were not allowed to move due to small available surface area and low height of cages (Hansen, 1994). On the other hand, broiler housed in cages stood significantly $(\mathrm{P}<0.05)$ more than those housed on floor as we hypothesized that cage raised birds did not given chance for resting on comfort floor due to sloped floor area of cages and absence of bedding material also birds respond to restricted floor area and low space allowance by decreasing crouching and walking and increasing standing idle. The obtained results agreed with Sosnowka-Czajka and Muchacka (2005) and Guemene et al. (2006), who found that birds show less lying in cages than floor- housed ones. Moreover, Chopra and Singh (1992); Fouzder et al. (1999); Fouad et al. (2008) and Abdel- Fatah (2008) observed that ingestive behavior was greater in floor housed birds than cage housed ones. In contrast to Tanaka and Hurnik (1992), our results revealed that wing stretch, leg stretch and both wing $\&$ leg stretch in cages were higher than floor system. From the obtained results, it was observed that those behavioural patterns were higher in cages than floor reared birds and the difference was statistically significant $(\mathrm{P}<0.05)$ which may be an indication of displacement activity in cages that might be expressed if the performance of a highly motivated behavior is restricted (Hansen, 1994). While our findings were in agreement with Abdel-Fatah (2008). These differences in behavioral patterns between the two housing system could reflect different methods by which birds try to adapte to the environment conditions. Behavioral patterns of birds in cages (mostly increase standing and decreased crouching and walking) is an indicator that this environment is stressful and adversely affect welfare. Appleby and Hughes (1991) observed that welfare was compromised more in cages than well run alternatives due to behavioral restriction and environmental deficiencies in cages.

2. Tonic immobility test: fear level, or more accurately stress level, is an important indicator of birds' welfare in commercial breeding. TI duration as a measure of fear can be influenced by the habitat in which birds live (Bilcik et al., 1998). Recording fear level was a part of evaluating welfare of broilers kept in two different housing systems. Results presented in Table (2) showed that housing system of broilers had a significant $(\mathrm{P}<0.05)$ effect on duration of tonic immobility test and in the number of attempts to induce, as it was higher in cages than floor system, which can be interpreted as higher level of fear in caged birds and therefore a lower welfare and more stressed conditions of poultry in cage systems. These findings agreed with Jones a Mills (1983); Mills and Faure (1986) and Biossy (1995) who stated that tonic immobility test is used for evaluating the level of fear of birds as an indication of stress and its duration increase in chronically stressed birds. Accordingly, Hansen et al. (1993) and Zapletal et al. (2010) who stated that duration of tonic immobility is increased in birds housed on cages than deep litter system.

3. Physiological indices: Mcfarlane and Curtis (1989) reported that heterophils: lymphocyte ratios were a more reliable indicator of stress. Cage reared birds had a marked heterophilia and basophilia while corresponding lymphoctopenia and higher (HLR) than floor reared broilers (Table 3). These findings are in agreement with Maxwell (1993); Al-Murani et al. (1997) and Fouad et al. (2008) who reported that 
$\mathrm{H}: \mathrm{L}$ ratio was higher in caged groups of birds than floor housed birds and attributed this to cage housing system which act as stressors for broiler chicks. On contrary, Mench et al. (1986) found that there is no difference in HLR between floor and cage housing systems for laying birds.

\section{CONCLUSION}

Our result revealed that welfare of broilers was adversely affect under cage housing system which indicated by behavioral patterns, higher fearfulness and $\mathrm{H}$ : $\mathrm{L}$ ratio. In conclusion, cages are not recommended as a housing system for rearing broilers from welfare point of view.

\section{REFERENCES}

Abdel-Fatah, E.M.M. (2008): Study on effect of some managerial factors on behaviour and performance of quail. M. V. Sc. Thesis, Fac. Vet. Med., Banha Univ.

Al-Murani, W.K.; Kassab, A.; Alsam, H.Z. and Althari, A.M.K. (1997): Heterophil/ Lymphocyte ratio as a selection criterion for heat resistance in domestic fowls. Br. Poult. Sci., 38: 159-163.

Appleby, M.C. and Hughes, B.O. (1991): Welfare of laying hens in cages and alternative systems: Environmental, physical and behavioral aspects. World's Poult. Sci. J., 47:109-128.

Bilcik, B.; Keeling, L.J. and Newberry, R.C. (1998): Effect of group size on tonic immobility test in laying hens. Behav. Processes., 43: 53-59.

Boissy, A. (1995): Fear and fearfulness in animals. Quarterly Review of Biology, 70:165-191.

Campo, J.L.; Gil, M.G.; Davila, S.G. and Munoz, I. (2007): Effect of lighting stress on fluctuating asymmetry, heterophil- to lymphocyte ratio and tonic immobility duration in eleven breeds of chickens. Poult. Sci., 86: 37: 45

Chopra, S.K. and Singh, R.A. (1992): Effect of hatching season and system of housing on the body weight, feed consumption, feed conversion and mortality of Japanese quail. Poultry today and tomorrow; 2(1-2): 1-6.

Fanatico, A.C.; Pillai, P.B.; Emmert, J.L. and Owens, C.M. (2007): Meat quality of slow and fast growing chicken genotypes fed low-nutrient or standard diets and raised indoors or with outdoor access. Poult. Sci., 86: 2245-2255.

Fouad, M.A.; Abdel Razek, A.H. and Badawy, E.M. (2008): Broilers welfare and economics under two management alternatives on commercial scale. Int. J. Poult. Sci., 7(12): 1167-1173.

Fouzder, S.K.; Ali, M.L.; Howlider, M.A.R. and Khan, N.R.M.Z. (1999): Performance of growing Japanese quails in cages, on slatted floor and on littered floor. Indian Journal of animal Sci., 69(12): 1059-1062.
Gallup, G.G. and Maser, J.D. (1979): Catatonia: Tonic immobility: Evolutionary underpinnings of human catalepsy and catatonia. In J.D. Maser, M.E.P. Seligman, (Eds) psychopathology: Experimental models. (pp. 334-357). San Francisco, CA: W.H. Freeman.

Guemene, D.; Guy, G.; Noirautt, J.; Destombes, N. and Faure, J.M. (2006): Rearing conditions during the force-feeding period in male mule ducks and their impact upon stress and welfare. Animal research., 55(5): 443-158.

Hansen, I. (1994): Behavioral expression of laying hen in aviaries and cages: Frequencies, time budgets and facility utilization. Br. Poult. Sci., 19:549-557.

Hansen, I.; Braastad, B.O.; Storbraten, J. and Tofastrud, M. (1993): Differences in fearfulness indicated by tonic immobility between laying hens in aviaries and in cages. Anim. Welf., 2: 105-112.

Hester, P.Y.; Mute, W.M.; Craig, J.V. and Albright, J.L. (1996): Group selection for adaptation to multiple hen cages: Hematology and adrenal function. Poult. Sci., 75: 1295-1307.

Jones, R.B. (1986): Tonic immobility in domestic fowl: a review. Worlds Poult. Sci. J., 42:82-96.

Jones, R.B. (1992): The nature of handling immediately prior to test affects tonic immobility fear reactions in laying hens and broiler. Appl. Anim. Behav. Sci., 34: 247-254.

Jones, R.B. and Faure, J.M. (1981): Tonic immobility (righting time) in layinghens housed in cages and pens. Appl. Anim. Ethol., 7: 369-372.

Jones, R.B. and Mills, A.D. (1983): Estimation of fear in two lines of the domestic chick: correlations between various methods. Behav. Processes; 8: 243-253.

Maxwell, M.H. (1993): Avian blood leucocyte responses to stress. World's Poult. Sci.J., 49: 34-43.

Mcfarlane, J.M. and Curtis, S.E. (1989): Multiple concurrent stressors in chicks. 3. Effects on plasma corticosterone and heterophil: lymphocyte ratio. Poult. Sci., 68: 522-527.

Mench, J.A.; Tienhoven, A.V.; March, J.A.; McCormick, C.C.; Cunningham, D.L. and Baker, R.S. (1986): Effects of cage and floor pen management on behaviour, production and physiological stress responses of laying hens. Poult. Sci., 65: 1058-1069.

Mills, A.D. and Faure, J.M. (1986): The estimation of fear in domestic quail, Correlation between various methods and measure, Biol. Beahv.; 11: 235-243.

SAS Institute (1996): User's guide: statistics. Cary, NC: SAS Institute.

Sosnowka-Czajka, E. and Muchacka, R. (2005): Effect of management system on behaviour and productivity of broiler chickens. Animals and environment, Vol. 2: proceedings of the 
$12^{\text {th }}-$ ISAH - congress on Animal Hygiene, Warsaw-Pollard, 4-8 September; 106-110.

Swain, B.K.; Sundaram, R.N.S.; Barbuddhe, S.B. and Nirmale, A.V. (2002): Influence of cage and deep litter rearing systems on the performance of broilers. Ind. J. Anim. Sci., 79: 467-469.

Tanaka, T. and Hurnik, J.F. (1992): Comparison of behaviour and performance of laying hens housed in battery cages and an aviary. Poult. Sci., 71(2): 235-243.
Webster, A.J.F. and Nicol, C.J. (1988): The case for welfare. In: Cages for the future, Cambridge Poultry Conference, Agricultural Advisory and Development Service, pp.: 11-21.

Wenger, R.M. (1992): Experience with get-away cage system. World's Poult. Sci., 46: 41-47.

Zapletal, D.; Suchy, P.; Strakova, E.; Vitula, F. and Kuchtik, J. (2010): Behaviour patterns of the cage-housed breeding flock of pheasents. Acta. Univ. Agri., Et. Silviculturae Mendelianae Brunensis, 215-220.

تقييم سلوكيات ورفاهية بدارى التسمين المرباه فى نظامين إسكان مختلفين

$$
\text { سارة السيل أبو اليزيل القزاز }
$$

E-mail: saraelkazaz2@gmail.com Assiut University web-site: www.aun.edu.eg

أجريت هذه التجربة لتقييم تأثثر نظام الإسكان (التربية في الأقفاص و التربية الأرضية) علي الأنماط السلوكية المختلفة ورفاهية بدارى

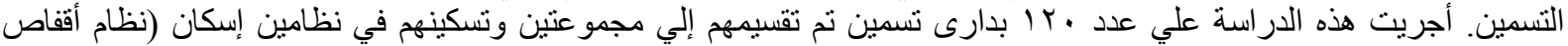

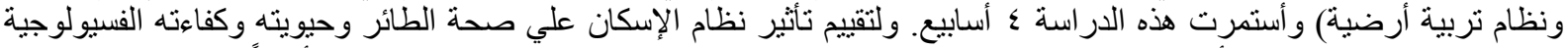

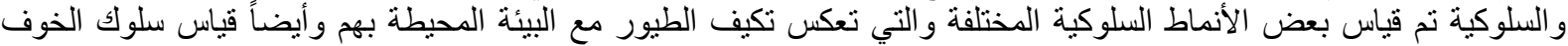

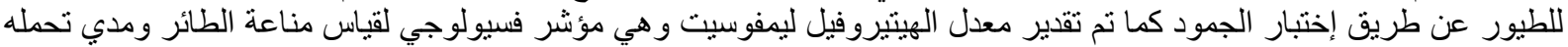

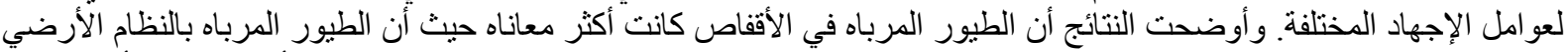

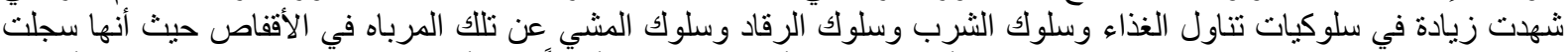

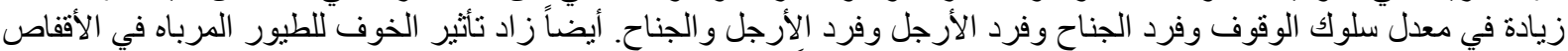

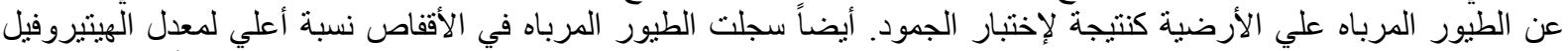

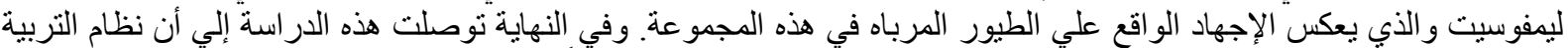

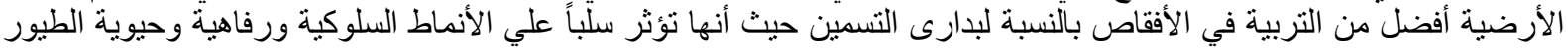

